\title{
JUAN RUIZ, ARCIPRESTE DE HITA, Y DON JUAN MANUEL, INFANTE DE CASTILLA: DOS MIRADAS PARA UN MUNDO EN CRISIS; O LA LITERATURA COMO HERRAMIENTA
}

\author{
De bone amor vient seance et bonté... \\ Teobaldo I de Navarra
}

Hace unos años -en el cuarto número de Verba Hispanica-, en un trabajo titulado Juan Ruiz, un hombre de nuestro tiempo ${ }^{1}$-fundamentado en lo sustancial por las lecturas que del Libro de buen amor, y de la figura de su autor, habían hecho Américo Castro ${ }^{2}$ y Julio Rodríguez Puértolas ${ }^{3}$-, comprobamos cómo la premeditada $-\mathrm{y}$, en absoluto, casualcomplejidad interna del Libro se cimienta no sólo en la diversidad de los materiales que contiene y lo construyen, sino, sobre todo, en la unidad de sentido ${ }^{4}$, que podríamos nombrar proto/novelesca, del conjunto entero: articulada, primero, en torno de la "ficción realista" -psicológica- del yo literario que los informa; en la lógica -intensamente dialéctica- que los organiza; y, finalmente, en la radical ironía mediante la que el autor desentraña y desactiva todos y cada uno de los -engañosos- discursos artísticos, religiosos e ideológicos dominantes en su tiempo; especialmente, el cortesano, el clerical y el monetario.

De modo que la inquieta y angustiada búsqueda del "amor bueno" -el que sacia y reconforta por entero-, que emprende el joven arcipreste protagonista -narrador de su propia peripecia- nos representaría "a cada uno de nosotros" -habitantes de su mismo mundo: he ahí su contemporaneidad-, enfrentándonos a fuerzas cósmicas e históricas -entre las que destacan la naturaleza, las estrellas, la muerte, las palabras armadas en discursos tramposos, y el dinero- que nos anulan, confunden y laminan; y contra las que la fe ya no basta; sobre todo, si consideramos que las leyes del "nuevo mundo" que ha emergido antagonista y pujante, dominado enteramente por el interés particular y la búsqueda del beneficio personal, en torno del nuevo Dios, nos plantean un dilema irresoluble a escala personal, el ajuste imposible de una realidad pública, ajena y hostil -que no dominamos-, al íntimo deseo de los "mundos interiores" -que nos domina-, inevita-

1 Matías Escalera, Juan Ruiz, un hombre de nuestro tiempo, en Verba Hispanica, IV, Ljubljana, 1994, pp 37-49.

2 Américo Castro, La realidad histórica de España, México, Porrúa, $1954\left(1966,3^{a}\right)$; y El Libro de Buen Amor del arcipreste de Hita, en Comparative Literature, IV, 1952, pp. 193-213.

3 Julio Rodríguez Puértolas, Juan Ruiz, un hombre angustiado, en Literatura, historia, alienación, Barcelona, 1976; y Juan Ruiz, arcipreste de Hita, Madrid, Edad, 1978.

4 A pesar de los que niegan tal unidad, o no logran ver más que una obra miscelánea y de aluvión. Tal es el caso de Francisco Rico, por ejemplo: Cf. "Entre el códice y el libro: notas sobre los paradigmas misceláneos y la literatura del siglo XIV", en Romance Philologie, LI, 2 (1997). Y los de Florencio Sevilla y Pablo Jauralde, que, en su edición del Libro (Barcelona, PPV, 1988), lo consideran como una "heterogénea miscelánea" de materiales sin la menor unidad discursiva, hilvanados por un yo "disperso e incapaz de dotar de unidad al relato". 
blemente abocado -a pesar de su parcial, eventual y transitoria realización: es el caso de doña Garoça- a la más dolorosa frustración.

Y, sin embargo, como señalábamos ya entonces -en un breve excurso- al comienzo del pormenorizado análisis que hacíamos del emblemático episodio de la monja, buena parte de los materiales simbólicos con los que se construye la historia de la seducción de doña Garoça, habían sido utilizados por el infante de Castilla, don Juan Manuel, con una finalidad y un sentido diametralmente opuestos: esto es, para afirmar y ejemplificar los nuevos valores y las nuevas reglas de juego; profundizar en ello, y extraer algunas conclusiones de este hecho, sigue siendo hoy precisamente nuestro objetivo.

Nada -apenas- sabemos de Juan Ruiz; bastante más, de don Juan Manuel -sobrino de Alfonso X, y nieto de Fernando III-, que dedicó toda su vida y sus energías a la acción política, a la conquista y a la detentación del poder; y que -como el Arcipreste- poseía exacta conciencia de los cambios que se estaban produciendo en la base social y cultural sobre la que se fundamentaban las relaciones entre los individuos y las clases sociales, como nos lo muestra cumplidamente en su Libro del Conde Lucanor (y, si no, ¿qué hace alguien como él contándoles el cuento de la lechera -el de doña Truhana- a los grandes señores de Castilla?). Son sus obras, en cuanto respuestas literarias -materiales e ideológicas- al mundo que habitaron, lo que verdaderamente nos interesa. Dos expresiones literarias dispares de la realidad/mundo que vivieron, y de los símbolos y los valores que la construyeron.

De momento, la obra del Arcipreste es la de un auténtico clérigo -quizás juristadel primer tercio del siglo XIV, que se mantenía al corriente y dominaba las claves del pensamiento y del arte literario de su tiempo, y que sostiene una posición crítica -una irónica distancia- con respecto a la tradición que recibe, y a los fundamentos mismos de la realidad que se construye a su alrededor. No cabe duda de que dominaba los principales géneros literarios cultos y populares, $\mathrm{y}$, si hacemos caso a Martín de Riquer, su Libro bien parece un "catálogo de los géneros en boga en su época". Aunque lo auténticamente concluyente es que ese catálogo -como veremos- no es un compendio aséptico -enciclopédico-, ni mucho menos reverencial, de los mismos, sino todo lo contrario; en realidad, es un repaso crítico -paródico y estudiadamente paradójico- que un "intelectual desplazado" -sin una clase, ni un estado ${ }^{5}$, de referencia nítidos- da a unos "discursos engañosos", que ocultan, más que desvelan, el conflictivo entramado de lo real.

La obra del infante don Juan Manuel es, sin embargo, un instrumento político didáctico- puesto al servicio de su clase: una herramienta de adoctrinamiento y educación

5 No sólo por las razones que apuntan Juan Carlos Temprano y Michael Solomon en su artículo La individualidad, el bien eficaz y el dilema de Juan Ruiz (Boletín de la Biblioteca Menéndez Pelayo, Santander, 1985, pp 15-35), la general des/ubicación, el desplazamiento social, jurídico, simbólico, práctico y cultural que afecta al bajo clero regular de la época; sino acaso también por su condición de intelectual -clérigo- averroísta. Cff. F. Márquez Villanueva: "El caso del averroísmo español: hacia la Celestina", en André Stoll (Ed.): Averroes dialogado. Un seminario interdisciplinar Reicherberger, Kassel 1998 (Actas del Seminario interdisciplinario del ZiF, Bielefeld, del 23 al 28 de junio 1997; pp. 121-132); del mismo autor, F. M. Villanueva, El Carnaval de Juan Ruiz, Arcadia. Estudios dedicados a Francisco López Estrada. Dicenda. Cuadernos de Filología Hispánica 6 (1987); pp. 177-188. Y Francisco Rico, El aristotelismo heterodoxo en el 'Libro de buen amor', Libro-homenaje a José A. Maravall. Madrid, Centro de investigaciones Sociológicas, 1986; pp. 271-297. 
-ideológica, política e incluso estética- de los clanes feudales castellanos; de ahí que uno de los temas vertebradores de la misma -en realidad, su leitmotiv- sea el poder: la conquista, el uso y la defensa del poder -del estado- en cualquiera de sus manifestaciones, ya sea social, económico, político, cultural o literario. La teoría -el sotil estilo- y la práctica literaria tienen para el infante un carácter indudablemente orgánico y colectivo; la escritura es un instrumento de clase.

Juan Ruiz, anticipándose a lo que dos siglos más tarde haría otro presunto alcalaíno, don Miguel de Cervantes, revisa, maneja y destripa todos los géneros habidos y por haber: desde los cantares de gesta a la literatura simbólica y alegórica; de la tradición didáctica y sapiencial, a la comedia escolar elegíaca latina -Pamphilus-; de la poesía goliárdica -Carmina Burana-, a la cortesana y trovadoresca; los fabliaux franceses o la autobiografía erótico amorosa de corte y motivo ovidianos -De vetula-; la literatura religiosa -bíblica y pastoral-, la canónica -Decretales- o la sermonaria; el debate poético y la jurisprudencia -Código de Justiniano-. La poesía juglaresca -oral y cantada- y la clerical; en lengua vulgar o en latín; además conoce y domina las corrientes filosóficas de su tiempo, y se identifica con una de ellas, el averroísmo aristotélico; se permite frecuentes incursiones en el universo morisco, y hace sus pinitos con el árabe coloquial -como sucede en el episodio de la joven mora (cs.1508-1512)-

El Arcipreste es un habitante de la ciudad mudéjar castellana (Alcalá y la ribera del Henares lo eran, a principios del siglo $\mathrm{XIV}^{6}$, en efecto), que cree hallar el amor bueno y limpio junto a una monja, doña Garoza, con nombre de sabor árabe -Alaroza, "la novia"-, y que para huir de la tristeza que le produce su muerte, se prenda de una bella morita. Un tipo, en suma, que abre su libro invocando al Dios creador del cielo y de la tierra: fuente del amor, y divino principio de la bondad y belleza de las mujeres, inmerso en la más genuina tradición de la mística -y de la teología- feminista cristiana, fundada por Hildegarda von Bingen?, dos siglos antes; al tiempo que cita al Aristóteles más rabiosamente materialista. "Por dos cosas trabaja el mundo, es cosa probada: por haber mantenencia y juntamiento con hembra placentera"' (c. 71). Y reconoce, de paso, el poder omnipotente de un nuevo Dios, el Dinero, que junto a la Naturaleza y las estrellas guían nuestra conducta. Sin contradicción aparente. Un poco de manduca cada día y un breve instante de olvido en los brazos de un amante placentero, y todo con la bendición de un Dios que comprende nuestra búsqueda y la bendice (cs. 694 y 697). Con lo dicho hasta aquí, bastaría para acabar -de una vez-con esa imagen vulgarizada y populachera de bon vivant rijoso, un poco mastuerzo y despreocupado, tan extendida -incluso entre círculos ilustrados- de nuestro autor.

6 El caso de Alcalá de Henares -o de Hita- es, en buena medida, representativo de esas tres ciudades en una. Durante toda la Edad Media la ciudad amurallada de Alcalá, de origen árabe, contiene tres barrios o sectores bien definidos que confluyen, sin embargo, en el mercado, bajo los soportales de la calle Mayor. Tres ciudades en una sola ciudad, esa es la clave del mudejarismo de Castilla la Nueva. Y esa realidad es la que, en parte, subyace al Libro del Arcipreste; la misma que detectaron, entre otros, Américo Castro, Lida de Malkiel y, luego, Criado de Val, Julio Rodríguez Puértolas o Juan Goytisolo, con su sugerente lectura del Libro desde Marraquech.

7 Cf. las tres antífonas de Sancta Maria, del manuscrito de Wiesbadem. De la segunda de las cuales, Quia ergo femina morte instruxit, proceden estos versos: ...et ideo est summa benedictio / in femina forma / pre omni creatura... (" $\mathrm{y}$ por ello la más grande de las bendiciones toma la forma de mujer, antes que la de cualquier otra criatura..."). $\mathrm{O}$ el famoso Scivias, del que hay traducción reciente en castellano. 
Todo lo contrario, quienquiera que escribiese el Libro de buen amor se nos aparece como un verdadero intelectual de su época; un autor de amplia formación y cultura, que compone una "autobiografía novelada" -la primera en lengua castellana ${ }^{8}$, y desde luego distinta de todo lo anterior'- irreductible a toda interpretación cerrada y excluyente, en la que resume su concepto entero del mundo: por dentro y por fuera; y planteada, además, como un reto a la inteligencia -concebida como "experiencia del mundo"- de sus potenciales lectores, a cuya sagacidad y capacidad de discernimiento apela constantemente; puesto que para pocos escritores como para el Arcipreste de Hita, la palabra escrita, el libro, puede ser fuente de conocimiento y autoridad intelectual, al mismo tiempo que trampa y laberinto en que podemos perdernos a nosotros mismos; hasta tal punto que, por momentos, se convierte en "narrador de sí mismo", de su propio decurso (c. 70), consciente de su propio poder, aquel que le confiere precisamente el juego de la imaginación: por el que los jugadores aceptan suspender, mientras dure la partida, las reglas que ordenan la realidad, para acceder precisamente a la realidad; un acto en apariencia inocente, en el que emisor y receptor se necesitan mutuamente, es verdad, y con el que nos divertimos, aprendemos y nos emocionamos, pero justo, por eso mismo, extremadamente peligroso, pues bordeamos constantemente el engaño.

"De todos los instrumentos yo, libro, soy pariente; según me toques, bien o mal, asi hablaré ciertamente..., si me sabes tratar, siempre me tendrás en mente" (c. 70). Depende de nosotros, de nuestra habilidad como lectores.

Juan Ruiz, quienquiera que fuese, tenía, pues, una intuición -y una convicción- muy desarrollada de la construcción dialógica -y dialéctica- de los textos literarios (frente al concepto unilateral y excluyente del Infante de Castilla o los clérigos del viejo Mester), como fenómenos y formas artísticas que representan, mediante sus propias leyes -distintas de las que rigen los acontecimientos reales; y aquí está el intríngulis-, la realidad misma, la entera y completa totalidad de los objetos que la componen. Realidad representada ("entiéndelo bien"), que no es la realidad misma, pero que, si no nos andamos listos, puede llegar a sustituirla, sin que nos apercibamos. Y a eso, confundir la literatura -el amor poético, por ejemplo- con la vida -el amor real-, según creía el misterioso arcipreste del siglo XIV, nos enajena de nosotros mismos y nos hace cometer errores que se pagan con dolor, soledad, violencia -doña Endrina- y frustración.

8 Así lo intuyó ya el mismo Marcelino Menéndez Pelayo en su Antología de poetas liricos castellanos, CSIC, Santander, 1944, vol. 1, p. 134. Y así lo han reconocido, mucho más recientemente, entre otros, Francisco Márquez Villanueva (Cf. la conclusión de su discurso de apertura del congreso internacional en torno a la obra del Arcipreste, organizado por el Centro para la Edición de los Clásicos Españoles, en Alcalá la Real, en mayo del 2002, titulado El celibato eclesiástico en el Libro de buen amor, cuyas Actas se encuentran a disposición en el Centro Virtual Cervantes); y, muy especialmente, Juan Goytisolo; por ejemplo, en el capitulo titulado "Medievalismo y modemidad: el Arcipreste de Hita y nosotros", de su Contracorrientes (Barcelona, Montesinos, 1985, pp. 14-21).

9 El hecho de que Isabel Uría (Panorama crítico del mester de clerecía, Madrid, Castalia, 2000) excluya al Libro de buen amor de la nómina de los libros clericales pertenecientes al Mester, y lo considere -siguiendo la estela de Francisco Rico- hasta cierto punto "inclasificable" (pp. 157-58) es de por sí significativo. Tanto como que Carmelo Gariano vinculase el Libro del Arcipreste a las obras de Boccaccio y de Chaucer en su libro Juan Ruiz, Boccaccio, Chaucer (Sacramento, califomia, Hispanic Press, 1984); o que Alberto Blecua, en su edición (Madrid, Cátedra, 1996, $3^{a}$ ), lo considere como una "anomalia literaria" (p. xxv), desvinculada de su entorno. 


\section{La época: un mundo que cambia}

La Reconquista prácticamente finalizada ${ }^{10}$, los partidarios de una monarquía fuerte y los que propugnaban el mantenimiento del viejo status quo feudal mantenían un estado de guerra civil continuo; los disturbios señoriales causados por esta pugna soterrada se sucedían unos a otros sin solución de continuidad, especialmente durante las minorías de edad de Fernando IV y Alfonso XI, con las sucesivas regencias de María de Molina y del colegio de nobles, del que llegó a formar parte el propio infante don Juan Manuel.

Concejos ciudadanos y clanes feudales, por su parte, se enfrentan, además, en un conflicto que llega, como el anterior, hasta los umbrales de la Edad Moderna. Las villas y ciudades libres, de añeja tradición en Castilla, debido a los privilegios acumulados durante los días más duros de la conquista y repoblación de la Meseta, libran su propia batalla contra la voracidad señorial. Los campesinos, empobrecidos por el abandono de sus amos, o sin expectativas de supervivencia aceptables, huyen de las tierras señoriales y se refugian en las pujantes ciudades, en donde quedan protegidos, de inmediato, por las nuevas leyes. Es la historia, en fin, de lo que Pierre Vilar y otros han llamado el estado semifeudal castellano. Los grandes reinos peninsulares, desde el siglo XIII, se dirigen, como en otras partes de Europa, hacia un modelo de Estado fuerte -la monarquía absoluta-, que pone inevitablemente en cuestión el poder de los grandes clanes feudales. Los monarcas de los siglos XIII y XIV (desde los reinados de Alfonso X el Sabio, en Castilla, y de Jaime I, en Aragón) tuvieron que batirse a muerte por el control de la soberanía contra sus respectivas noblezas: en los campos jurídico y político, y en el de batalla. El caso de Alfonso X el Sabio es ejemplar, sobre todo, en el campo jurídico. Su estrategia culmina con la promulgación de las Partidas, fundamento legal de la nueva monarquía. En Aragón, por el contrario, Pedro III el Grande, a causa de la conquista y disputa de Sicilia, y de su política de expansión mediterránea, en las Cortes celebradas en Tarazona el año 1283, resuelve el conflicto con las noblezas aragonesa y catalana firmando el privilegio de la Unión o Hermandad de nobles aragoneses y catalanes, por el cual el monarca "reconocía la superioridad de la costumbre y renunciaba a continuar la política de fortalecimiento del poder monárquico y a la recuperación de los bienes usurpados a la Corona" durante el conflictivo periodo del rey Jaime I.

Por su parte, la burguesía castellana, en gran parte judía, aún no está sometida a las persecuciones que tendrán lugar a partir de la Gran Peste. El Estado y sus principales instituciones se consolidan en un proceso imparable que llevará a Castilla a hegemonizar la futura confederación con el reino de Aragón, a finales del siglo siguiente; mostrando, una vez más, como crisis política y desarrollo social no son siempre fenómenos incompatibles. A pesar de los sucesivos periodos de estancamiento económico e involución social que sacuden el lento y progresivo acceso de la nueva clase al poder, el dinero y las mercancías fluyen y se adueñan de las vidas de los hombres; el nuevo Dios se asienta también en la ciudad castellana; y Juan Ruiz, y el Infante, perciben con toda claridad este hecho fundamental.

En cuanto a la Iglesia Romana viene arrastrando -de lejos- una crisis institucional y moral que desembocará en el llamado Cisma de Occidente. Iglesia e imperio, además,

10 Después de la victoria del río Salado, en 1340, contra los benimerines -con Alfonso XI a la cabeza-, del antiguo poderío andalusí, sólo quedaría ya el pequeño reino de Granada, tutelado por Castilla. 
pugnan por el control político de las instituciones. Y las futuras potencias europeas se ven inmersas en un conflicto a escala continental, por el control de nuevos territorios, que se conocerá como la Guerra de los Cien Años; conflicto que se suma a los anteriores; que afecta fundamentalmente a Francia e Inglaterra, pero que termina por implicar, en diversas fases del mismo, a otros reinos y territorios, como es el caso de Castilla.

En el plano ideológico y filosófico, se enfrentan dos posiciones irreconciliables. La llegada de los comentarios de Averroes sobre Aristóteles a las aulas universitarias y la enseñanza pública, luego, del canon aristotélico crean una corriente de pensamiento materialista que no deja de afectar a la escolástica oficial, y desencadena, al principio, una reacción neoplatónica y agustiniana ${ }^{11}$-Duns Scoto, v. g.-, e inmediatamente, una ola de condenas y anatemas contra los averroístas, que arrastra incluso al tomismo ortodoxo.

Un siglo y medio antes, a partir del rotundo y sonoro fracaso de la orden del Císter en la cruzada contra los Albigenses o Cátaros del mediodía francés, entre los años 1204 y 1209 , se inició la paulatina sustitución del monje por el fraile, igual que el monasterio feudal cedió el paso a la catedral ciudadana; es un cambio lento y progresivo, pero imparable; es además manifestación de otros cambios más profundos en la sociedad y en la cultura europeas. La creación de las órdenes mendicantes en 1206 -los predicadores de santo Domingo-, y en 1209 -los fraticelli o menores de san Francisco-, supone la adáptación de los cuerpos regulares de la Iglesia al nuevo mundo que se avecina. Los nuevos frailes poseen movilidad y capacidad de presencia en el medio urbano, su ámbito de actuación son las calles y las plazas de las ciudades; se adaptan rápidamente a las nuevas circunstancias $y$, sobre todo, predican y, al principio, practican la pobreza evangélica, con lo que también hacen de ariete interior en la profunda reforma institucional y moral en la que anda metido el papado desde finales del siglo XII, y que culmina con los decretos del cuarto Concilio de Letrán (1212-1215), sobre la educación y rearme moral del clero. A grandes rasgos, los franciscanos se identifican con una experiencia sensible y emotiva de la religión, acorde con el espíritu de su fundador; mientras que los predicadores de santo Domingo, desde el principio, cumplen una función de celosos vigilantes de la ortodoxia, como intelectuales o como inquisidores. Todo ello, al mismo tiempo que se impone una nueva mentalidad religiosa que se debate entre la emoción, la rebeldía contra las instituciones, los sentimientos y la pureza dogmática; dentro de la cual habría que enmarcar el emergente culto a la Virgen, del que los franciscanos participan activamente, coetáneo casualmente de la explosión cortés y caballeresca, y en el que la Dama celestial es el objeto amoroso y la destinataria de los sentimientos, como cercana mediadora, ante un lejano, hierático e imponente Cristo Rey instalado en la cumbre y vértice inalcanzable de la pirámide celestial, como los reyes, los señores feudales -y los obispos rapaces- lo están en la pirámide terrenal (¿no son éstos el Dios y la religión del Infante?). Así, pues, cuando Juan Ruiz decide excluir -expresamente- a san Francisco de la cohorte de frailes, clérigos, monjas y monjes de todas las órdenes que salen a recibir a don Amor (c. 1328); o cuando canta los gozos de la Virgen y dedica los mismos adjetivos a ésta (cs. 19, 50, $1045-46$ y 1635), que a doña Venus (cs. 583d-585) o a Trotaconventos (c. 701), resaltan-

11 ¿No se manifestaría, acaso, esta tensión en las interpolaciones añadidas al Libro del Arcipreste, especialmente en su llamado "prólogo en prosa", en abierta -agustiniana- contradicción con el resto del libro -esencialmente "averroísta"-, al que supuestamente prologa? 
do el carácter maternal, amable y mediador de las tres figuras femeninas ${ }^{12}$, no lo hace sin intención, ni en vano, toma un partido distinto al de los clérigos del siglo anterior, y al del Infante, el del arte como expresión del "mundo interior" individual: de sus emociones, sentimientos, pasiones y conflictos personales.

Finalmente, al control y monopolio del sexo, alcanzado, mediante la institución del sacramento del matrimonio, a mediados del siglo XII, y a la vieja segregación sexual entre hombres y mujeres, por la que éstas se convierten, primero, en el instrumento preferido del pecado $y$, luego, en la causa primordial del mal; se suma ahora una nueva segregación entre los varones célibes -eclesiásticos-, y los varones casados -seglares-, que coincide en el tiempo con la institución de otro sacramento, el de la penitencia incluidas la confesión oral de los pecados y la reparación inmediata de la pena-; instrumentos que se revelaron eficacísimos no sólo, de puertas afuera, en la lucha de la Iglesia contra las casas reales imperiales, francesas o alemanas, sobre todo, desde el extraño caso de Leonor de Aquitania -mujer de dos reyes-; sino también mecanismos inestimables para el ordenamiento y la vigilancia de las conductas clericales, de puertas adentro. El dominio absoluto sobre el sexo y la consiguiente demonización de la mujer, como fuente de pecado e impureza, por un lado; y la estricta regulación de la confesión de los pecados y de la penitencia, por otro -como nos advierte el historiador francés Georges Duby, en su estudio sobre el cambio en la significación de la figura de María Magdalena a lo largo de la baja Edad Media-, se convirtieron en dos potentes herramientas de la reforma eclesiástica, emprendida ya en los siglos XI y XII por la orden del Císter -desde Cluny-, y retomada después por las órdenes mendicantes en los siglos XIII y XIV. Pero también -y especialmente-, en dos impresionantes fuerzas alienadoras, $y$ enajenadoras de las conductas, volcadas hacia el control y el apaciguamiento de las conciencias revoltosas y de las conductas tenidas por disolventes.

Y, sin embargo, en el Libro de Buen Amor, la mujer es fuente de gozo y de bondad, y Dios es su garante (cs. 108-09). El amor sexual no sólo no. es malo y pecaminoso, sino que es inevitable, natural y reparador. El celibato, una quimera (cs. 1500-01). La confesión, un problema de simple jurisdicción canónica, aplicada, eso sí, a un fantoche de la imaginación, como es don Carnal, o un mero expediente, sin repercusión moral alguna (c. 1501). Juan Ruiz no sólo tiene en cuenta la realidad de su tiempo a la hora de escribir su libro, es que los mismos fundamentos de la realidad son su objetivo primordial; esto es, las líneas de fuerza, las trampas y los compromisos que se manifiestan, u ocultan detrás de las conductas, de las costumbres, hábitos, sentimientos e ideas que manejan los individuos, los estamentos sociales o las instituciones culturales en un tiempo concreto.

Se ha hablado de faltas de referencias concretas a los acontecimientos históricos de la época en el Libro del Arcipreste ${ }^{13}$; pero no hace falta referirse al exilio dorado de la corte papal en Avignon, a las guerras civiles castellanas o la "creciente industria lanar", para nombrar literariamente aquella realidad. Es como quitar validez a la capacidad de representación de la realidad del hombre del siglo XX a La metamorfosis de Kafka, por-

12 Hace tiempo que André Michalski y Alicia C. Ferraresi (De amor y poesía en la España medieval: prólogo a Juan Ruiz, México, Colegio de México, 1976, pp. 43-118) señalaron el idéntico carácter de terceras de la Virgen y de Trotaconventos.

13 Así lo hace, por ejemplo, G. B. Gybbon Monypenny en la introducción de su edición del Libro, en Clásicos Castalia (Madrid, 1988). 
que no aparecen reflejadas en la historia de Gregorio Samsa las luchas de los sindicatos ferroviarios bohemios, o la pobreza del proletariado industrial europeo de la época. O quejarse porque Beckett no nos dice la marca del automóvil en que aparecerá Godot.

\section{Literatura: poder y reflexión}

La línea de fuerza dominante en los relatos castellanos -entre los siglos XIII y XIV-, esencialmente educativa, desconoce casi por completo la individualidad -el mundo interior: psicológico- como núcleo constructor del texto. Desde la "singularidad política" del Poema de Mio Cid -anticipo de lo que viene-, de la que habla Colin Smith, y las intenciones propagandísticas y aleccionadoras de las obras del Mester: las vidas de los santos y los Milagros de Nuestra Señora, de Berceo; el Libro de Alexandre, o el Poema de Fernán González; hasta la didascalia social y política del infante don Juan Manuel y su Conde Lucanor, por ejemplo; en todos estos relatos, se da una general apropiación de personajes, leyendas populares, cuentos y apólogos tradicionales, con el fin de integrarlos en relatos didácticos -unívocos-, con una marcada intención ideologizadora.

A ellos, precisamente, se enfrenta el Libro de buen amor, y como botón de muestra valdrían perfectamente los diferentes usos y sentidos que adquiere la fábula de El zorro que se hizo el muerto (ejemplo XXIX), en el "espejo de príncipes" del Infante don Juan Manuel, y en el "librete" de Juan Ruiz, integrada en la extraordinaria polémica entre doña Garoça y la vieja Trotaconventos ${ }^{14}$. Salvando las distancias, es lo que sucede si comparamos el viejo Cid, héroe y símbolo político de una clase -la de los caballeros e infanzones-, con el joven Rodrigo de los romances y canciones populares, símbolo de la rebeldía y del trágico destino individuales.

En efecto, no hay caso más revelador para comprender el carácter instrumental -e ideológico- de la literatura que la lectura comparada del Libro del Arcipreste y el del Conde Lucanor, del Infante de Castilla; coincidentes en un mismo tiempo y espacio históricos, pero absolutamente dispares-. El aliento poético procede -en ambas- de un mismo "impulso de explicación" del mundo para los otros; pero, en realidad, dan dos realizaciones -materializaciones- opuestas de la escritura. Mientras que, tras el Libro del conde Lucanor, se adivina "un yo instrumental y práctico, integrado por una visión del mundo que se sustenta en una aspiración antigua de dominio y de servidumbre; que se manifiesta como una especial violencia individual" -decíamos en el artículo citado al comienzo-; en el caso del Libro del Arcipreste, el yo que se explica -que no es aquel que narra- se manifiesta de un modo conflictivo, abierto y dialéctico.

"Para don Juan Manuel, la realidad entera es un objeto de dominio, la conciencia se manifiesta como conciencia de dominación del hombre sobre la mujer, del hombre, como especie, sobre la naturaleza; de cada individuo sobre los demás individuos, de unos colectivos, digamos las clases, sobre los otros: de los cristianos sobre los moros, de los amos sobre los siervos... Y todo a partir de una falsa conciencia de sí mismo, en los términos elaborados por Erich Fromn, cuyo origen habría que buscarlo en la ciega confianza del infante de Castilla en la recién descubierta potencia de un yo arrogante y voraz", sobre el que se va a construir -se ha construido ya- el nuevo mundo que angustia al Arcipreste.

14 Absolutamente incomprendida por Miguel Martinez, en su artículo La fábula del zorro que se hizo el muerto, en Juan Ruiz y don Juan Manuel, en el Boletín de la Biblioteca Menéndez Pelayo, LX, Santander, 1984, pp. 65-98. 
Pero "el ejercicio del poder -concluíamos entonces-, como bien sabe Marco Aurelio, resulta un hecho básicamente alienante, no tanto para quienes lo soportan como para quien lo ejercita". Y el deseo absoluto de dominio absoluto -la sumisión a la esfera del dominio-, limita, a la postre -también-, la capacidad de discernimiento, de desarrollo estético $^{15}$ y creativo.

La forma y estructura de los textos, así como la retórica a partir de la cual se articulan éstos, son señales inequívocas que nos conducen -tanto como los contenidos- a la visión del mundo en que se sustentan. Si el infante don Juan Manuel se apropia de la tradición apologética desde una perspectiva de clase -en la que cada fábula y apólogo se convierte en un indicador para la instrucción política de sus colegas-, sin resquicio para el comentario, ni distancia irónica ${ }^{16}$ apreciable; Juan Ruiz lo hace desde otra bien distinta: dialógica -esto es, abierta al comentario-, distanciada e irónica ${ }^{17}$. El Arcipreste no defiende cuotas de poder y de dominio sobre los demás, sino que filtra y desarticula, con ojo crítico -risueño, unas veces, y paródico, otras-, todo aquello que ve, que oye, que le cuentan o que recibe bajo la forma de ficciones literarias y discursos ideológicos oficiales. Otra prueba de la acción limitadora de la conciencia como estructura de dominación es esa especie de incapacidad del Infante para la ironía, para la ambigüedad y para el humor. La retórica de don Juan Manuel es aleccionadora, unilateral, y se sustenta en la pulcra y aseada reiteración de las mismas fórmulas, funciones y secuencias, sin concesiones a lo diferente, a lo otro, sin espacio para la respuesta dialógica -ni, por tanto, para el comentario: la moraleja nos lo impide-, pues ni siquiera admite la posibilidad de que tal respuesta -ni comentario- exista. Detrás del oscuro y "sotil" modo, no se esconde más que una calculada instrumentalización del arte por una minoría, aquella que detenta el poder político, social y cultural. Y ésta es precisamente la trampa que el Arcipreste trata de desmontar con su aparentemente "desorganizado" modo de plantear las cosas, pues tras sus continuas advertencias sobre el sentido oculto de su libro, no habría otra cosa que una firme confianza en la capacidad de todo ser humano para descubrir no sólo la lógica que le asiste, sino las trampas que las ficciones -y relatos- de los poderosos -llámense amor cortés, arte de amar, seducción elegíaca, cantar de gesta, sermón, pecado, culpa o confesión- nos trazan. Por eso, el Arcipreste nos resulta alguien cercano, conocido -y simpático-, aunque no le comprendamos del todo; pues, en realidad, es "uno de los nuestros". Y es que, desde el siglo XIV, hay una literatura -objetiva- de la seguridad y de

15 Rafael Argullol, en un artículo titulado Arte y crimen (publicado en el diario El País, Madrid, 20/08/06); analizando los casos de Amo Breker, el escultor de Hitler, el de Leni Riefenstahl, la cineasta de Hitler, y el de Albert Speer, el arquitecto de Hitler; escribe lo siguiente: Más interesante para nosotros es prestar atención al giro estético que practican los tres una vez han entrado en la zona negra del nacionalsocialismo. Speer deja de lado sus primeros proyectos, funcionales y austeros para incorporar, paso a paso, los delirios arquitectónicos de Hitler, el frustrado estudiante de arquitectura austriaco. El Reich necesita contemplarse en la eternidad de la piedra y Speer se pone al frente de sus sueños megalómanos... Riefenstahl cambia el panteísmo cinematográfico de alta montaña por los decorados marciales de los aquelarres nazis en Múnich o Berlin. Breker, por su parte, renuncia a toda experimentación en su escultura, hasta entonces muy inspirada por Rodin, para concentrarse en el hieratismo $y$ la rigidez del poder...

16 Pues, como John Maynard Keynes descubre, al volver la vista atrás, a los días del famoso grupo de Bloomsbury, el sarcasmo y la ironía ejercidos por los superiores deviene sólo banalidad y dominación.

17 Y Lukács consideraba que la ironía era el camino de la objetividad, a través del cual el héroe moderno encuentra la exacta dimensión de su desplazamiento y de su soledad. 
la potencia -esencialmente educativa-, y otra -subjetiva- de la impotencia y de la estupefacción, aglutinada en torno de los miedos y las desilusiones del yo ("mundo interior" apenas redescubierto) expuesto -arrojado- a un "mundo exterior", sentido ya como un ámbito hiriente y hostil; Juan Ruiz, quienquiera que fuese, abrió en Castilla -tal vez, en Europa- esa veta, que de tanto excavarse (siglo tras siglo; en una realidad, además, en la que, hace ya mucho tiempo, se decretó la "desaparición del sujeto") se muestra completamente agotada. 